\title{
Two new naturalized species from South Korea, Polygonum ramosissimum Michx. (Polygonaceae) and Spergularia bocconi (Scheele) Graebn. (Caryophyllaceae)
}

\author{
Ji-Eun Choi, Jung-Hyun Kim, Jeong-Ki Hong ${ }^{1}$ and Jin-Seok Kim* \\ Plant Resources Division, National Institute of Biological Resources, Incheon 22689, Korea \\ ${ }^{1}$ Freshwater Biodiversity Research Bureau, Nakdonggang National Institute of Biological Resources, Sangju 37242, Korea \\ (Received 29 August 2016; Revised 12 September 2016; Accepted 13 September 2016)

\section{한국 미기록 귀화식물: 미국갯마디풀(마디풀과)과 끈적털갯개미자리(석죽과)} \\ 최지은 · 김중현 · 홍정기 ${ }^{1} \cdot$ 김진석* \\ 국립생물자원관 식물자원과 \\ 1국립낙동강생물자원관 담수생물다양성연구실
}

\begin{abstract}
Two naturalized species, Polygonum ramosissimum Michx. (Polygonaceae) and Spergularia bocconi (Scheele) Graebn. (Caryophyllaceae) were found along the southwest seashore of the Korean Peninsula. Polygonum ramosissimum is distinguished from other species in the same genus taxa as follows: not granular achens, lanceolate or oblanceolate leaves. Spergularia bocconi is distinguished from other species in the same genus taxa by having glandular hairs on stems, leaves, peduncles, and outer surfaces of sepals. We provide here a description and photographs of two species and a key to related taxa in Korea.
\end{abstract}

Keywords: Polygonum ramosissimum, Polygonaceae, Spergularia bocconi, Caryophyllaceae

적 요: 미기록 귀화식물인 Polygonum ramosissinum Michx. (마디풀과)와 Spergularia bocconi (Scheele) Graebn. (석죽과)를 한반도 서남해안에서 발견되었다. 미국갯마디풀로 신칭한 P. ramosissinum은 잎이 도피침형 이거나 피침형이며, 수과는 돌기가 없는 형태적 특징으로 속내 근연종들과 구분된다. 끈적털갯개미자리로 신 칭한 S. bocconi는 꽃이 달리는 윗부분의 가지, 줄기, 잎에 샘털이 있으며, 특히 꽃자루와 꽃받침잎 바깥 면에 많은 샘털을 가지고 있는 형태적 특징으로 속내 근연종들과 구분된다. 본 연구는 미기록 귀화식물 2종에 대한 기재와 화상자료를 제공하고, 검색표를 작성하였다.

주요어: 미국갯마디풀, 마디풀과, 끈적털갯개미자리, 석죽과

마디풀과(Polygonaceae Juss.)는 약 50속 1,120여 분류군이 전 세계에 걸쳐 광범위하게 나타나며, 주로 북반구의 온대, 아열대지역에 널리 분포하고 아프리카 남부, 호주, 뉴질랜 드, 중앙아메리카 및 남아메리카에서도 분포한다(Reveal,
1978; Park, 1988; Hong, 1992; Brandbyge, 1993; Pendry, 2004). 그 중 마디풀속(Polygonum L.)은 약 230 분류군이 분포한다 (Li et al., 2003). 국내에는 마디풀(P. aviculare L.), 애기마디 풀(P. plebeium R. Br.) 등의 5-9분류군이 분포하며, 모든 분

\footnotetext{
*Author for correspondence: foko@korea.kr
} 
류군들이 자생식물이다(Park and Hong, 2007; Jung et al., 2010; Lee et al., 2011; Korea National Arboretum, 2014).

석죽과(Caryophyllaceae Juss.)는 80속 약 2,000여 분류군 이 북반구에 넓게 나타나며, 주로 온대지역에 널리 분포 하고 서아시아, 서중국 및 히말라야에서도 분포한다 $(\mathrm{Lu}$ et al., 2001). 그 중 갯개미자리속[Spergularia (Pers.) J. Presl \& C. Presl]은 약 25여 분류군이 분포한다( $\mathrm{Lu}$ et al., 2001). 국내에는 갯개미자리[S. marina (L.) Besser]와 유럽개미 자리(S. rubra J. Presl \& C. Presl) 2분류군이 분포하며(Lee et al., 2011; Korea National Arboretum, 2014), 이중에 유럽 개미자리는 귀화식물이다(Park, 2009).

본 연구는 새롭게 발견된 마디풀과 및 석죽과의 미기 록 귀화식물 2 분류군에 대하여 형태적 특징 기재, 국명부 여, 국내에 분포하는 근연분류군들과의 검색표를 작성하 여 그 특성을 보고하고자 한다.

\section{분류군의 기재}

Polygonum ramosissimum Michx. Fl. Bor.-Am. 1: 237238, 1803.

국명: 미국갯마디풀(Mi-guk-gaet-ma-di-pul; 국명 신칭)

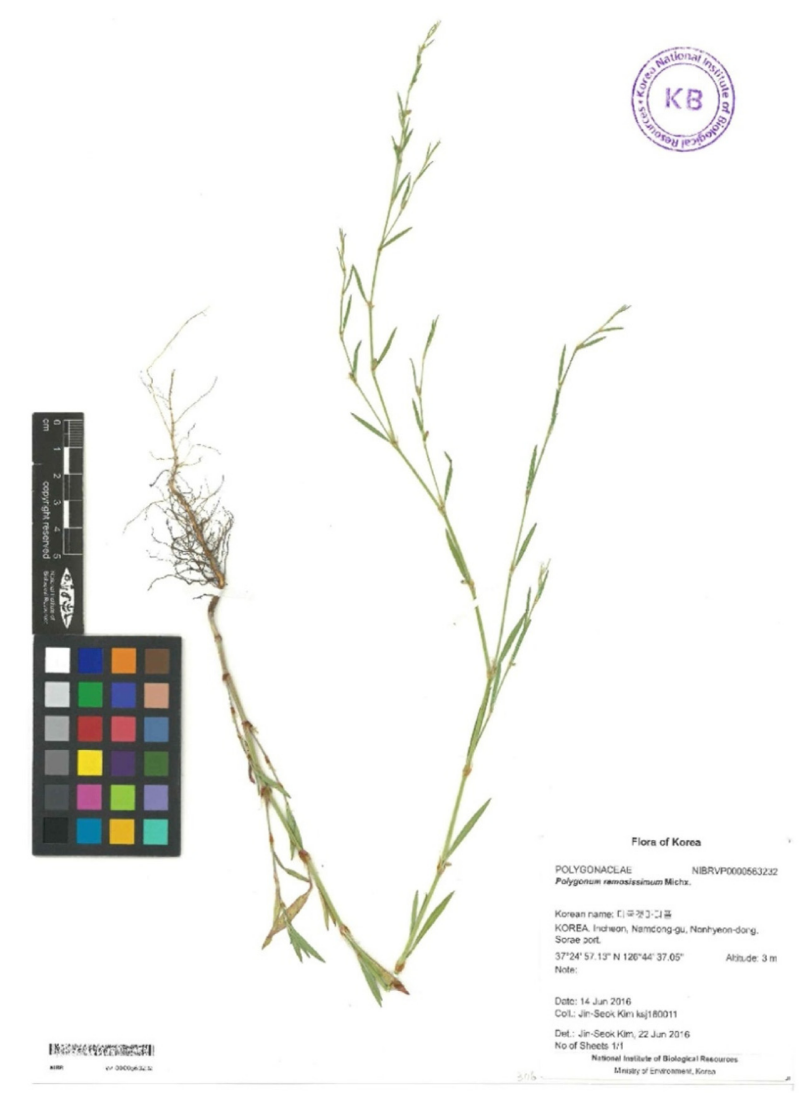

Fig. 1. Voucher specimen of Polygonum ramosissimum Michx. (KB).
1 년생 초본이다. 줄기는 길이 $15-40(-100) \mathrm{cm}$ 이고 곧 추 자라며 흔히 아래쪽에서 가지가 많이 갈라지지만 환 경에 따라서는 가지가 갈라지지 않기도 한다. 전체는 황 록색-회록색 또는 밝은 청록색을 띠며 털이 없다. 잎이 말 라도 검게 변하지 않는다. 잎은 어긋나며 두 가지 형태를 보인다. 길이 8-70 mm의 피침형(또는 도피침형)-난형이 고 줄기와 같은 황록색-밝은 청록색이다. 잎 끝은 뾰족하 거나 길게 뾰족하며 가장자리는 뒤로 약간 말린다. 양면 에 털이 없고 뒷면 중앙맥은 도드라지며 잎자루는 길이 2-4 mm이다. 탁엽은 길이 6-12(-15) $\mathrm{mm}$ 의 원통형이고 막질이며 끝부분은 흔히 길게 갈라져 갈색의 섬유질화 된다. 꽃은 6-7월에 피고 가지 끝이나 윗부분의 잎겨드랑 이에서 1-4개씩 모여 달린다. 꽃자루는 길이 2.5-6 mm이 다. 화피는 길이 2.2-3.6 mm이며, 연한 황록색이고 간혹 가장자리는 황색, 분홍색 또는 백색이다. 수술은 3-6(-8) 개이고 암술대는 3개이다. 열매(수과)는 길이 2-3.5 mm 의 삼릉형상 난형이고 흑갈색이며 화피보가 짧거나 약간 길다(Figs. 1, 2).

분포: 북아메리카 원산, 한국(서해안 바닷가 갯벌).

관찰표본: KOREA. Gyeonggi-do: Hwaseong-si, Songsanmyeon, Gojeong-ri, Sihwaho, 26 Jul 2016, J. S. Kim kjs160016, 160017, 160018 (KB). Incheon-si: Namdong-gu, Nonhyeon-dong, Sorae port, 14 Jun 2016, J. S. Kim kjs160010, 160011 (KB).

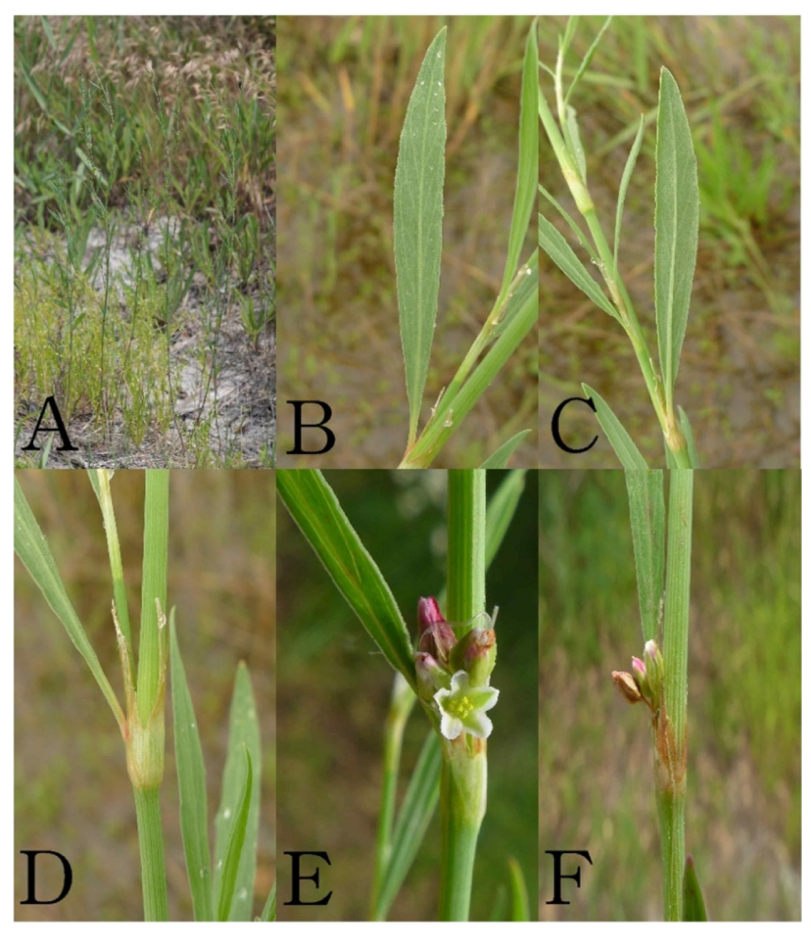

Fig. 2. Photographs of Polygonum ramosissimum Michx. A. Habit. B. Adaxial side of leaves. C. Abaxial side of leaves. D. Stipule. E. Flower. F. Fruits. 


\section{근연분류군과의 검색표}

1. 상부의 잎이 작고 떨어지기 쉬워 꽃이 수상화서 모양 이 된다. 수과는 화피 밖으로 상당히 돌출한다

갯마디풀 P. polyneuron

1. 상부의 잎은 지속적이며, 수상화서 모양이 아니다. 수과는 화피에 싸였거나 약간 돌출한다

2. 전체의 길이는 50-60 cm이고, 줄기는 곧추 자란다

3. 잎은 타원형이거나 피침형이며, 수과에 작은 돌기가 있다 ….. 큰옥매듭풀 P. fusco-ochreatum

3. 잎은 도피침형이거나 피침상이며, 수과는 돌 기가 없다 ........ 미국갯마디풀 P. ramosissimum

2. 전체의 길이는 $10-40 \mathrm{~cm}$ 이고, 줄기는 누워 자라거 나 땅을 기며, 드물게 서는 형태를 취한다

4. 소화경 상단 끝부분에 관절이 있고, 수과는 작 은 반점이나 알갱이로 이루어 진 줄무늬가 빽 빽하며, 윤채가 없거나 약간 있다

5. 수과는 삼각상 난형이고 뭉툭하며 윤채가 없다 마디풀 P. aviculare

5. 수과는 타원형이고 줄모양의 작은 돌기가 있으며 윤채가 약간 있다

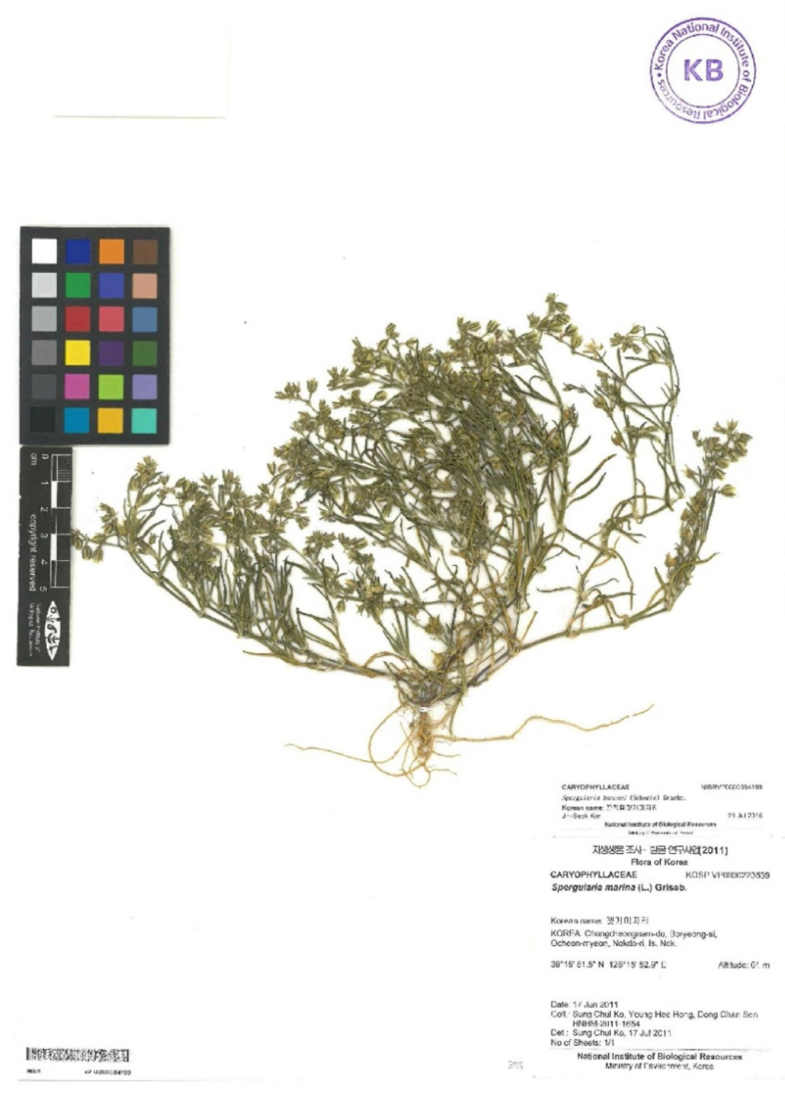

Fig. 3. Voucher specimen of Spergularia bocconi (Scheele) Graebn. (KB).
부산마디풀 P. humifusum

4. 소화경 $1 / 2$ 부분에 관절이 있고, 수과는 매끈하 며, 윤채가 있다 ............ 애기마디풀 P. plebeium

Spergularia bocconi (Scheele) Graebn. Syn. Mitteleur. Fl. 5: 849, 1919.

국명: 끈적털갯개미자리(Kkeun-jeok-teol-gaet-gae-mi-jari; 국명 신칭).

1 년생 또는 2년생 초본이다. 줄기는 길이 $5-25 \mathrm{~cm}$ 이고 아랫부분에서 가지가 많이 갈라지며 땅으로 기거나 비스 듬히 위로 자란다. 꽃이 달리는 윗부분의 가지, 줄기, 잎에 는 샘털이 있다. 잎은 마주나거나 모여나며 길이 $1-3.5 \mathrm{~cm}$ 의 다소 굽은 선형이고 흔히 다육질이다. 탁엽은 막질이 며 길이 $1.5-4.5 \mathrm{~mm}$ 의 삼각형-넓은 삼각형이고 끝부분이 짧게 뾰족하다. 꽃은 4-8월에 백색 또는 분홍색으로 피며 가지 윗부분의 잎겨드랑이에서 1(-3)개씩 달린다. 꽃자루 는 길이 2-5 mm이며 꽃이 지면 $1 \mathrm{~cm}$ 정도로 길어지면서 아래로 처진다. 꽃자루와 꽃받침잎 바깥면에는 샘털이 밀 생한다. 꽃잎은 난형상 긴 타원형이고 5 개이며 흔히 위쪽

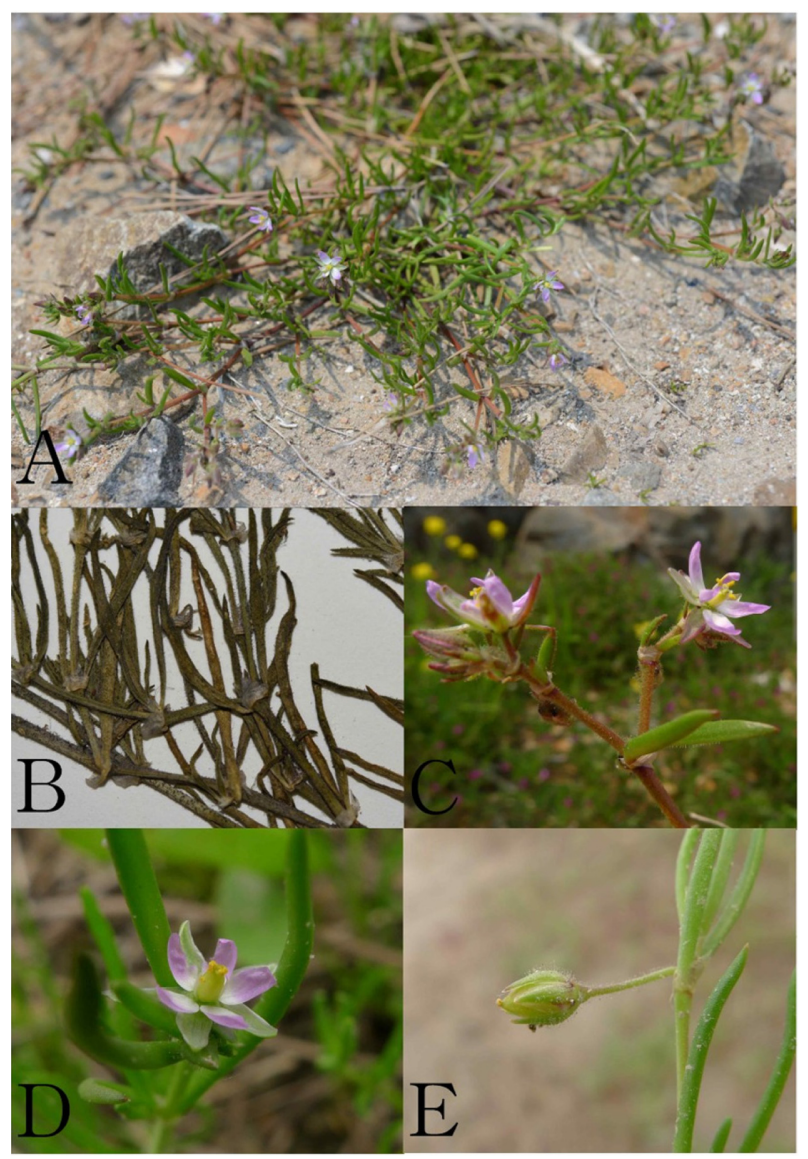

Fig. 4. Photographs of Spergularia bocconi (Scheele) Graebn. A. Habit. B. Leaves. C. Glandulour hair inflorescence. D. Flower. E. Fruits. 
으로 $2 / 3$ 는 분홍색이고 나머지 밑부분은 백색이다. 꽃받 침잎은 길이 2-3.5(-4.5) $\mathrm{mm}$ 의 좁은 삼각형이고 길이는 꽃잎과 비슷하거나 2 배이다. 수술은 흔히 4-5(-8)개이고 암술대는 3 개이다. 열매(삭과)는 길이 2-4 mm이며 꽃받 침잎과 갈이가 비슷하거나 더 길다. 종자는 밝은 갈색이 며 길이 $0.5 \mathrm{~mm}$ 정도의 넓은 난형이다(Figs. 3,4 ).

분포: 유럽(지중해)원산. 한국(서남해안 바닷가 갯벌 및 모래땅).

관찰표본: KOREA. Chungcheongnam-do: Boryeong-si, Ocheon-myeon, Nokdo-ri, Nokdo Island, 17 Jun 2011, Ko et al. HNHM-2011-1654, 1655 (KB); Taean-gun, Wonbukmyeon, Hwangchon-ri, Hagampo beach, 21 Jul 2005, Park et al. 2685 (KB). Gyeonggi-do: Ansan-si, Danwon-gu, Daebudong, Daebudo Island, 11 Aug 2011, C. S. Lee, leecs20110576 (KB); Hwaseong-si, Songsan-myeon, Gojeong-ri, Sihwaho, 26 Jul 2016, J.S. Kim kjs 160013, 160014, 160015 (KB); Siheungsi, Jeongwang-dong, Sihwaho, 29 Sep 2007, Kim et al. 1149, 1150 (KB). Incheon-si: Ganghwa-gun, Gilsang-myeon, Seondu-ri, Ganghwado Island, 22 Sep 2009, H. J. Kim, 09708, 1230 (KB); Gyodong-myeon, Yanggap-ri, Binjang port, 2 Jul 2013, Kim et al. Gyodong130522, 130523 (KB); Seo-gu, Gyeongseo-dong, Gongchoncheon stream, 8 Jun 2016, J. S. Kim, kjs160019 (2 sheets, KB); Gyeongin Ara Waterway, 3 Aug 2013, Kim \& Kim, KIMJH13298, 13299 (KB); Namdong-gu, Nonhyeon-dong, Sorae wetland, 14 Jun 2016, J. S. Kim, seed16046 (KB). Jeju-do: Seogwipo-si, Seongsan-eup, Siheungri, 7 Jun 2012, Moon \& Kang, 3527 (3 sheets, KB). Jeollabukdo: Buan-gun, Julpo-myeon, Upo-ri, Julpo-man tide land, 24 Jul 2010, H. D. Son, Im50572 (KB). Jeollanam-do: Haenamgun, Hwasan-myeon, Haechang-ri, Haechang port, 2 Oct 2004, Shin \& Lim, 4154 (KB); Jindo-gun, Gunnae-myeon, Na-ri, 23 May 2014, Lim \& Ham, NAPI-J20140357 (3 sheets, KB); Sinan-gun, Aphae-eup, Bunmae-ri, 30 May 2011, Hyun \& Seo, NAPI-J20110134 (KB); Lim \& Ham, NAPI-J20140307 (3 sheets, KB); Songgong-ri, 24 May 2012, Na \& Seo, NAPIS2012017 (KB); Bigeum-myeon, Gulim-ri, Bigeum Island, 2 Jun 2011, Seo et al. NAPI-J20110221 (KB); Wando-gun, Geumil-eup, Chungdong-ri, Mt. Mangsan, 1 May 2011, Ahn \& Yoon, 347093-50424 (5 sheets, KB); Gogeum-myeon, Sedongri, Gegeum Island, 22 Apr 2015, Seo et al. NAPI-20150078 (3 sheets, KB); Soan-myeon, Soan Island, 15 Jun 2008, Kim et al. SB30827, 30931 (KB); Yeonggwang-gun, Yeomsan-myeon, Bongnam-ri, 7 Jul 2009, H. T. Im, E09092 (KB).

\section{근연분류군과의 검색표}

1. 탁엽의 길이는 $1.5-3 \mathrm{~mm}$ 로, 합생하며 넓은 삼각형 이다.
2. 줄기와 잎에 털의 거의 없으며, 잎이 다육성이다 ….. 갯개미자리 S. marina

2. 줄기 윗부분의 가지, 잎, 꽃자루, 꽃받침잎에 샘털 이 밀생한다 ……..... 끈적털갯개미자리 S. bocconi

1. 탁엽의 길이는 $3-5 \mathrm{~mm}$ 로, 이생하며 긴 삼각형이다..... 유럽개미자리 S. rubra

\section{고 찰}

미국갯마디풀은 북아메리카 원산 귀화식물로 아프리 카 남부, 호주, 뉴질랜드, 중앙아메리카 및 남아메리카에 분포하고 있다(Reveal, 1978; Park, 1988; Hong, 1992; Brandbyge, 1993; Pendry, 2004). 국내에서는 인천시 소래습 지 공원과 경기도 화성시 시화호에서 확인되었다. 본종은 식물 전체가 밝은 회록색 또는 황록색이며, 잎이 피침형 상이라는 형태적 특징에 의해 속내 근연종들과 구분된다.

인천시 소래습지의 생육지는 명아주(Chenopodium album var. stenophyllum Makino), 나문재[Suaeda glauca (Bunge) Bunge], 갯개미자리[Spergularia marina (L.) Griseb], 갯개미 취(Aster tripolium L.), 참새귀리(Bromus japonicus Thunb.), 산 조풀[Calamagrostis epigeios (L.) Roth], 갯겨이삭(Puccinellia coreensis Hack. ex Honda) 등과 혼생하고, 경기도 화성시 시화호 생육지에서는 나문재, 해홍나물[Suaeda maritima (L.) Dumort.], 갯개미자리, 마디풀(Polygonum aviculare L.), 갯길경[Plantago major f. jezomariima (Koidz.) Ohwi], 갯개 미취, 사데풀(Sonchus brachyotus DC.), 갯하늘지기 [Fimbristylis ferruginea var. sieboldii (Miq. ex C. B. Blarke) Ohwi], 산조풀, 갈대(Phragmites communis Trin.) 등이 함께 관찰되었다.

미국갯마디풀은 미국의 일부 주(메릴랜드, 뉴햄프셔 등) 에서는 멸종위기종으로 지정하여 보호조치를 취하고 있 으며(Freeman and Reveal, 2005), 일본에서는 귀화식물로 취급하고 분포가 알려져 있으나, 실체 확인이 되지 않고 있다(Shimizu, 2003).

끈적털갯개미자리는 유럽 지중해 원산 귀화식물로 서 아시아, 서중국 및 히말라야에 분포하며(Lu et al., 2001), 일본에서는 귀화식물로 보고되었다(Shimizu, 2003). 국내 에는 경기도, 인천시, 제주특별자치도, 전라남도, 충청남 도의 서남해안에서 분포가 확인되었다. 본종은 속내 근연 종인 갯개미자리와 유사하나, 가지, 잎, 꽃자루, 꽃받침잎 의 샘털이 밀생한다는 형태적 특징으로 구분된다.

본 분류군은 자생종인 갯개미자리와 매우 유사하기 때 문에 그동안 종에 대한 인식 부족으로 오동정이 많았을 것으로 보여 국립생물자원관 고등식물표본수장고 $(\mathrm{KB})$ 에 보관되어 있던 갯개미자리속 표본을 재동정·검토하였 다. 그 결과, 상당수의 표본이 갯개미자리로 오동정되었 으며, 2004년도에 이미 채집된 표본이 있는 것으로 보아 그 전부터 국내에 정착하여 귀화된 것으로 생각된다. 
처음으로 실체가 확인된 인천시 공촌천의 생육지는 해 홍나물, 취명아주(Chenopodium glaucum L.), 나문재, 마디 풀, 소리쟁이(Rumex crispus L.) 등과 혼생하고, 소래습지 의 공원내 생육지는 산조풀, 갯개미자리, 갯질경, 애기비 쑥(Artemisia nakaii Pamp.) 등이 함께 관찰되었다.

상기의 두 종은 상층 식생이 없는 개활지의 갯벌 및 모 래땅에 주로 분포하고 주변 식생과의 종간 경쟁에서 우위 를 점하고 있다. 또한 끈적털갯개미자리의 경우는 결실률 이 높고 종자수가 많아 분포 확산이 빠르게 진행될 것으 로 예상된다. 현재까지 이 지역에서 교란된 식생이 나타 나고 있지 않지만, 이들을 대상으로 지속적이고 적극적인 모니터링과 생육환경 변화에 예의 주시할 필요가 있을 것 으로 판단된다. 앞으로 서남해안지역에서 생물상적 조사 가 지속적으로 수행된다면 추가적인 분포지가 확인될 개 연성이 많을 것으로 생각된다.

\section{사 사}

본 논문은 정부(환경부)의 재원으로 국립생물자원관의 지원을 받아 수행되었습니다(NIBR201601104).

\section{Literature Cited}

Brandbyge, J. 1993. Polygonaceae. In The Families and Genera of Vascular Plants. Vol. 2. Kubitzki, K. (ed.), Springer, Berlin. Pp. 531-544.

Freeman, C. C. and L. J. Reveal. 2005. Polyganaceae Juss. In Flora of North America North of Mexico. Vol. 5. Magnoliophyta: Caryophyllidae. FNA Editorial Committee (ed.), Oxford University Press, New York. Pp. 216-601.

Hong, S.-P. 1992. Taxonomy of the genus Aconogonon (Polygonaceae) in Himalaya and adjacent regions. Symblae Botanicae Upsalienses 30: 1-117.

Jung, S. Y., Y. M. Lee, S. H. Park, S. M. Yun and J. C. Yang. 2010. Polygonum plebeium R. Br. (Polygonaceae): an unrecorded species in Korea. Korean Journal Plant Taxonomy 40: 247250. (in Korean)
Korea National Arboretum. 2014. Korean Plant Names Index. Retrieved Jul. 22, 2016, http://www.nature.go.kr/kpni/ index.do.

Li, A., B. Bao, A. E. Grabovskaya-Borodina, S.-P. Hong, J. McNeill, S. L. Mosyakin, H. Ohba and C.-W. Park. 2003. Polygonaceae. In Flora of China. Vol. 5. Ulmaceae through Basellaceae. Wu, Z.-Y., P. H. Raven and D. Y. Hong (eds.), Science Press, Beijing and Missouri Botanical Garden Press, St. Louis, MO. Pp. 277-350.

Lee, B. Y., G. H. Nam, J. Y. Lee, C. H. Park, C. E. Lim, M. H. Kim, S. J. Lee, T. K. Noh, J. A. Lim, J. E. Han and J. H. Kim. 2011. National List of Species of Korea (Vascular Plants). National Institute of Biological Resources, Incheon. Pp. 139, 143-144. (in Korean)

Lu, D., Z. Wu, L. Zhou, S. Chen, M. G. Gilbert, M. Liden, J. McNeill, J. K. Morton, B. Oxelman, R. K. Rabeler, M. Thulin, N. J. Turland and W. L. Wagner. 2001. Caryophyllaceae. In Flora of China. Vol. 6. Caryophyllaceae through Lardizabalaceae. Wu, Z.-Y., P. H. Raven and D. Y. Hong (eds.), Science Press, Beijing and Missouri Botanical Garden Press, St. Louis, MO. Pp. 1-113.

Park, C.-W. 1988. Taxonomy of Polygonum section Echinocaulon (Polygonaceae). Memoris of the New York Botanical Garden 47: 1-82.

Park, C. W. and S. P. Hong 2007. Polygonaceae Juss. In The Genera of Vascular Plants of Korea. Flora of Korea Editorial Committee (ed.), Academy Publishing Co., Seoul. Pp. 334-351.

Park, S. H. 2009. New illustrations and Photographs of Naturalized Plants of Korea. Ilchokak, Seoul. Pp. 106-119. (in Korean)

Pendry, C. A. 2004. Monograph of Ruprechtia (Polygonaceae). Systematic Botany Monographs Vol. 67. American Society of Plant Taxonomists, Ann Arbor, MI. Pp. 1-113.

Reveal, J. L. 1978. Distribution and phylogeny of Eriogonoideae (Polygonaceae). Great Basin Naturalist Memories 2: 169-190.

Shimizu, T. 2003. Naturalized Plants of Japan. Heibonsha, Tokyo. Pp. 44-64. (in Japanese) 